\title{
Erratum to: Effects of nutraceuticals on quality of life and sexual function of perimenopausal women
}

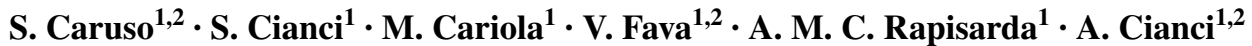

Published online: 17 February 2017

(C) Italian Society of Endocrinology (SIE) 2017

\section{Erratum to: J Endocrinol Invest}

DOI 10.1007/s40618-016-0500-2

Due to a typing mistake the term "quecitine" was included in the text. It doesn't find a validation context; the correct word is "quercetin" as it is systematically reported in the scientific literature.

The online version of the original article can be found under doi:10.1007/s40618-016-0500-2.

S. Caruso

scaruso@unict.it

1 Department of General Surgery and Medical Surgical Specialties, Gynecological Clinic of the Policlinico

Universitario, Via S.Sofia 78, 95124 Catania, Italy

2 Research Group for Sexology, Catania, Italy 